\title{
Introducing Instruction into a Personalised Learning Environment
}

\author{
Frank Kurzel \\ University of South Australia, Adelaide, Australia
}

Frank.Kurzel@unisa.edu.au

\begin{abstract}
In this paper, we describe the theory and techniques we have employed within a pre-existing learning environment to provide personalised features for students within an IT related domain. Our system is based on concepts, both declarative and practical, that can be combined in different configurations, and displayed in different media formats to account for different students. We also use instructional objects to represent higher level instructional content that play particular roles in a methodology. These objects could be groupings of concepts presented to the learner, or some instructional template that plays another role within the methodology.

Students have access to all course metadata through a range of tools, along with web based tools to scrutinise and access information stored about them. This includes both the formal assessment data along with the individual settings that drive the environment.
\end{abstract}

Keywords: Personalised Learning Environment, personalisation features, instruction, learning styles, course metadata, student profiles.

\section{Introduction}

In a quest to provide improved Learning Environments (LE) for students at tertiary level in particular, researchers (Eklund \& Brusilovsky, 1998; Kurzel, Slay, \& Hagenus, 2003; Martinez, 2001a; Sampson, Karagiannidis, \& Kinshuk, 2002; Voigt \& Swatman; 2003) are focussing on personalising the experience through a Learning Management System (LMS) that attempts to tailor the LE to the individual. This tailoring can impact on the:

- content that is accessed and the media forms used in its representation

- groupings of the content and the relationships between them

- method of instruction employed and the learning styles supported

- interactions that the student has with tutors and other students

- computer interface that the student interacts with and perhaps modifies

Material published as part of this journal, either on-line or in print, is copyrighted by Informing Science. Permission to make digital or paper copy of part or all of these works for personal or classroom use is granted without fee provided that the copies are not made or distributed for profit or commercial advantage AND that copies 1) bear this notice in full and 2) give the full citation on the first page. It is permissible to abstract these works so long as credit is given. To copy in all other cases or to republish or to post on a server or to redistribute to lists requires specific permission from the publisher at Publisher@InformingScience.org
The World Wide Web (WWW) has been introduced progressively into educational environments to support teaching. Typically, this has been either through the provision of hypertextually linked educational artefacts that are distributed over the WWW and accessible through browsers, or 
Introducing Instruction into a Personalised Learning Environment

through the provision of both course metadata and student information to support the administration of the instructional materials. The overlaying of student and course information provides the foundation for the establishment of a student-centred LE.

Previous work (Eklund \& Brusilovsky, 1998; Kurzel, Slay, \& Chau, 2002; Slay, Quirchmayr, Kurzel, Slay, \& Hagenus, 2003) has discussed how the WWW and Adaptive Hypermedia (AH) has the potential to individualise instruction in higher education. Interbook (Brusilovsky, Schwarz, \& Weber, 1996) for example, demonstrated personalising features that could account for individual differences in knowledge. Brusilovsky used the term concept when referring to the elementary pieces of knowledge within a domain. This notion of a concept as a fundamental unit has subsequently been employed in instructional systems. It corresponds to a Sharable Content Object (SCO) as specified with the SCORM standard (SCORM 2003); SCOs are fine grained learning resources that are considered instructionally inert.

I have further argued (Kurzel, 2003) that in some domains (i.e. information technology), it is appropriate to further type these concepts as either declarative, or practical; the later are usually linked to the former. Previous work also demonstrated that these concepts could exist in a range of media forms with the LMS capable of displaying them.

The concepts of the AH system described above, constitute learning objects as defined by IEEE Learning Technology Standards Committee specification; the subsequent typing the semantic links between concepts adds low level instructional significance to the concept within the instructional domain. However, other Instructional Objects (IOs) are required to either aggregate concepts for particular purposes, or provide templates that outline some instructional phase within the methodology being employed. These IOs then need to be mapped to a phase (Allert, Dhraief, \& Nejdl, 2002) within some instructional methodology.

Within this paper, we enumerate and justify the personalisation characteristics possible within a LE. Further, we describe the design goals and decisions undertaken in the development of a prototype of a Personalised Learning Environment (PLE) for the presentation of course materials within an Information Technology related area. We build upon previous work with the goal being a PLE that provides greater flexibility and satisfaction as students interact in individual ways with a tailored LE.

\section{Personalising Features}

Learning Environments supporting information technology related courses, as Maurer (2002) suggests, are complex systems that should support:

- content reusability

- tools for student access and manipulation

- administration tools for teachers

- communication facilities for the participants and

- interactions that enable reflection of the learning process

Further, they should support the preferred learning styles of the stake holders in the process. Martinez's (2001b) holistic approach enumerates the characteristics of different learning orientations and recommends strategies to support these within the LE; different learner orientations require different instructional methodologies. Voigt and Swatman (Voigt \& Swatman, 2003 ) further note that the learner should have a more fundamental role in understanding the LE and should subsequently choose the methodology that best suits their orientation; the environment then is individually adaptable (Oppermann, Rashev, \& Kinshuk, 1997) and instruction is personalised. 


\section{Personalising Content}

Students undertake courses with different skills and knowledge; components of the course may already be accounted for either totally, or partially. By providing direction at the content level via annotated links (Brusilovsky, 2000), each student encounters individualised content. Links allow the individualised traversal of the semantic network of concepts that represent the domain knowledge (domain model). Some AH systems also use frame-like representations with sets of attributes to provide a finer resolution of a concept. The ability to present different content constitutes adaptive presentation. The student overlay model with perhaps stereotyping (Kay,, 2000) built in, can be used to drive the LMS in presenting the student with appropriate content. Student access to these settings then provides an adaptable environment for students who wish to scrutinise and modify their settings.

Recent experiments (Alty, 2002) correlating learning styles (Felder, 1993) and multimedia forms supports the notion that students might want to decide on different multimedia presentation formats; dual coding theory would support this assertion. A component of the LE might then allow the student to specify their preferred media format without necessarily prohibiting access to others. Jonassen, Peck, and Wilson (1999) take the position that the true worth of multimedia and hypermedia might be obtained through the learner constructing knowledge via the use of technology, rather than as a mode of delivery. In IT related instructional environments, students can create a range of multimedia and hypermedia artefacts to satisfy the requirements of the course, and to satisfy their own individual needs, i.e. creating their own media players.

\section{Individualising Content Groupings}

Instructor organised groupings of content within the domain model, may not necessarily meet the goals of the student, nor may they meet the student's view of the content. Providing tools in the LE to group concepts, allows students to establish their own personalised structures of information. Bookmarking is certainly an effective way of aggregating concepts within LEs. However, the original instructor generated course model provides the scaffolding for some learner orientations to fall back on.

The instructor too, is often forced into a particular methodology because of the tight coupling of instructional model with the domain model. To break this nexus, there needs to be a separation of the domain model from the instructional model as with Intelligent Tutoring Systems (ITS). Instruction then needs to provide the mechanisms for defining not only the sequence that the learning resources are to be presented to the user, but the additional instructional resources that might support the methodology being employed.

\section{Personalising Instruction}

Instructional objects that play particular roles (Allert et al., 2002) in different methodologies, may group instructionally independent concepts into packages as per the SCORM (SCORM, 2003) specification. AMLE (Kurzel, 2002) for example, groups a week's worth of concepts and related practical concepts into sessions. Alternately, an instructional object might simply be an artefact that plays a role in the methodology; for example, it might be the specification of a problem that a module of work will be based on.

To support other teaching methodologies, the metadata defining instructional objects needs to be defined to drive the delivery. In a Problem Based Learning (PBL) scenario, a student would be presented with links to all the appropriate artefacts specified to support the different roles within this methodology. This is analogous to the session view discussed above except at the instructional level. This is not to say that an instructional object might not refer to the lower level con- 
Introducing Instruction into a Personalised Learning Environment

cepts discussed before. It might for example, be a practical that introduces some required, background practical concepts; this practical might also be used in other methodologies.

Personalisation could also be considered from the instructor level; instructors too should be able to select the particular instructional methodology they wish to pursue and specify it within the metadata for the course.

The establishment of such systems requires:

- an enumeration of applicable methodologies in the domain;

- the creation of appropriate instructional templates for each of the phases within the methodology;

- the incorporation of metadata into the system.

\section{Personalised Interactions}

The students need to also have access to all of the information about both their interaction with the course content and their progress through it. Tutors too need convenient access to the central repository of both course and student information. Reporting mechanisms need to be in place for both students and instructors to display relevant information. Educational hypermedia systems typically account for this through the use of the course, student, and assessment models.

Communications facilities should also exit to allow on-line students within practicals to discuss problems, or to simply discuss particular content-based issues. Students might want to personalise the student groupings and activate them when they are logged onto the system. To support this, these groupings have to be enumerated in the student models.

In an online environment as with an normal face to face instructional situation, students should be able to choose the tutor they work with, or indeed ask help from. The learning environment should be able to provide both synchronous and asynchronous interactions to enable a variety of forms of interaction.

\section{Personalising the Interface}

Personalising the interface can at its simplest level, refer to issues such as changing colours, backgrounds, sounds etc. This personalisation is not insignificant because it provides the users with an individual platform to work within; there is an ownership aspect to the interface. This can also include the addition of tools that allow the user to incorporate their own reflections on particular educational items, and indeed to incorporate their own content representations. These could be textual or indeed aural. This extends the notion of accessibility within the interface and fosters a personalisation that enters into the domain of the instructional concepts.

The notion of ownership of the interface can be extended through the creation of hypermedia and/or multimedia artefacts within the workspace as a result of assignment work, or as a result of personal interest. Coupled with the above, it can be seen that IT related areas are well served by these notions. There appears a good match between these areas of endeavour and constructivist principles (Jonassen et al., 1997) where students actively involve themselves in the learning process, creating items and placing them into their workspace or on the WWW, searching out content and skills, and satisfying authentic tasks. 


\section{Instruction within the PLE}

The domain for this research is the instructional content associated with Multimedia Concepts, an introductory course within the multimedia studies stream of a Bachelor of Arts. The aim of this course is to provide the foundational knowledge and skills required to create and utilise a range of media items within multimedia presentations. Students undertaking this course come with a range of backgrounds, from a number of different Programs. A unique feature of the of the main interface within the architecture (Figure 1) is that it has been implemented in Macromedia Director (the main development environment used in the course); students can add to and modify the interface as required. It subsequently provides us with an IT related learning environment to evaluate personalisation characteristics.

Multimedia artefacts can be created within this course and included in their environment, enabling some personalisation at the interface level. The resulting assignment/project work can also

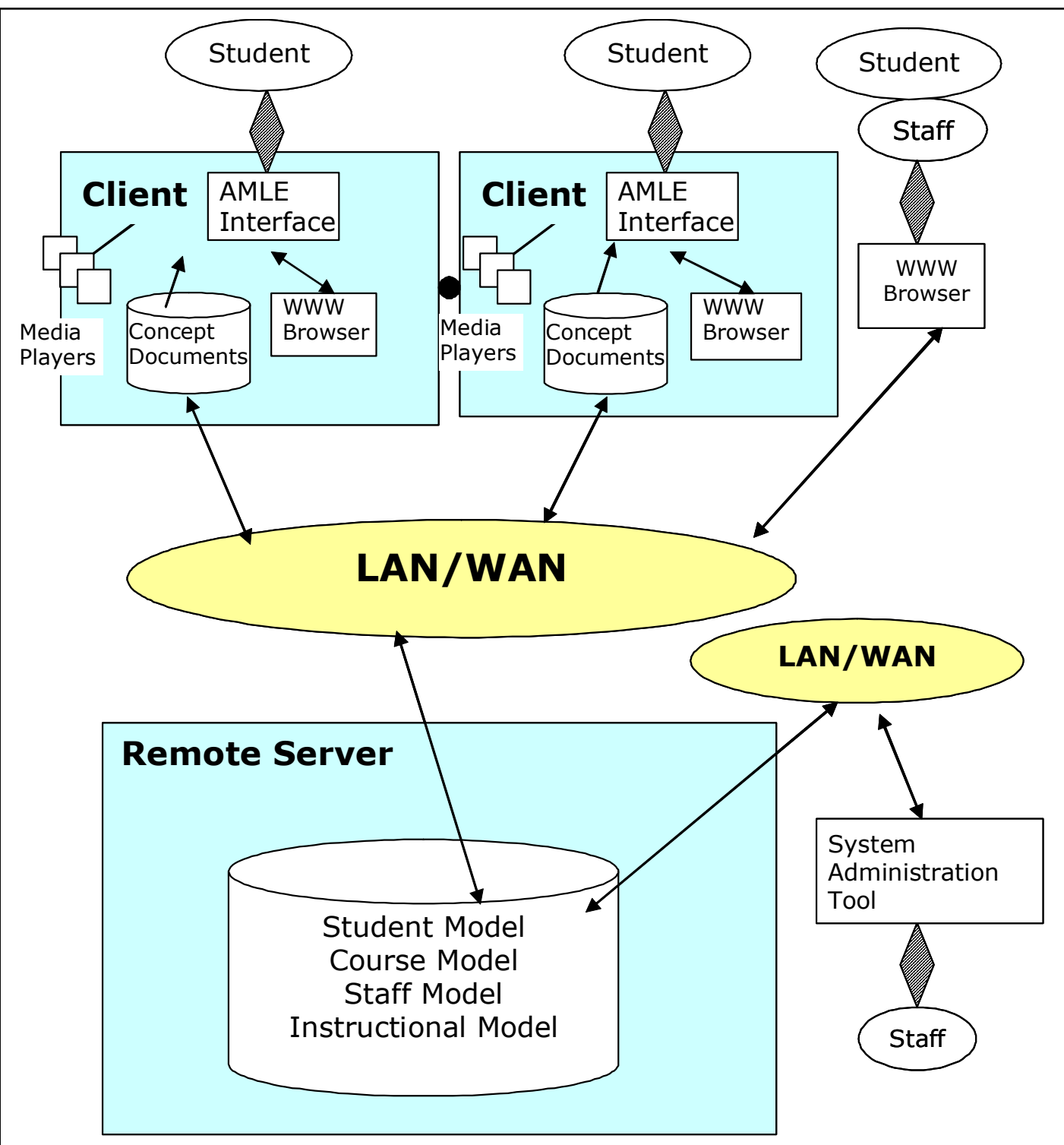

Figure 1: PLE Architecture 
Introducing Instruction into a Personalised Learning Environment

be embedded into their interface. Practical activities can directly relate to the main interface, thereby strengthening the notion of ownership and the personalisation of the interface.

The testing at the concept level is based on a competency model which is administered online; where a concept is a skill or task, students are asked to complete a task and have it registered manually. For example, if the concept we are dealing with is the scanning of an image, the concept might be demonstrated and the student asked to perform the task; completion of this task then is manually registered. A more formal assessment model including activities like assignment, exams, test, investigations etc., is included within the overlay model. Scrutability should also pertain to both the course model (pre-requisites, outcomes) and the formal assessment, and students should be able to view their standing in the course at anytime.

The sequencing service within SCORM's LMS is incorporated within the instructional model; declarative concepts can be packaged via metadata into weekly session, and practical concepts into practical tasks. To support other methodologies; instructional objects can be packaged to represent a problem within the PBL paradigm. The phase background knowledge (Allert et al., 2002) for example, requires the identification and location of relevant information. The template in this case might provide information about what should be searched for and how to go about it in the learning environment. Another object might describe the algorithm involved.

The fact that a learning objects can have a role within a number of theories, constitutes a network. The fact that some phases precede others is analogous to the pre-requisite relationship of the concepts. With more instructional methodologies defined in terms of phases with corresponding learning objects in the learning environment, the student too might select a particular methodology; here the learning environment would automate the delivery by searching the network of instructional objects.

Students interact with their profiling data through a web based interface that allows them to:

- view their current formal assessment standing

- scrutinise and edit personal information

- $\quad$ specify personalisation information like:

○ practical group members

○ learning style specification

$\circ$ media preference

○ standing within the course - beginner, intermediate, advanced

○ instructional preference

A tracking component has been built-in to monitor changes made to the editable preference settings. Accesses of all components through the main interface, can be monitored, providing quantitative validation of any student specified settings.

\section{Current and Future Work}

Our major concern has been to personalise the learning environment for our students since we recognise that our students' backgrounds and cultures have given us a wide range of learning styles and expectations among our students. Currently, we have created a range of hybrid browsers with varying interfaces to access the course model; a number of players and tools have been created to display and search for multimedia/hypermedia content that could be stored locally, or 
somewhere on the WWW. The metadata supporting a range of methodologies based on the roles played by particular IOs within a methodology, has been placed into the instructional model.

We continue to investigate constructivist learning environments within an IT speciality, where we actively engage the student, provide tools for the construction of new student knowledge and provide communication structures that enable students to work collaboratively with non-trivial problems. Other instructional methodologies, and educational activities underpinned by the constructivist philosophy (in particular problem solving) are being explored.

The processed logged data representing how the students have interacted with the PLE, along with questionnaire responses, will be used to validate the usefulness of the personlisation characteristics espoused. This data then has the potential of feeding back into the system and enhancing the features employed.

\section{Conclusion}

We have established a personalised learning environment that adapts to prior knowledge through the use of link annotation; we have also introduced stereotypes into the overlay student model and have coupled this to different content presentations. The metadata supporting alternate instructional methodologies has been embedded in the LE to support automation within the LMS. This metadata is based on the roles particular instructional objects play within the methodology of choice. A range of other tools like search engines, indexes, help, tutorial groupings etc. support the LE.

Our addressing system utilises the WWW but does not exclude the local file system for larger media items. The dynamic components of the learning environment i.e. assessment, course structure, instructional methodology etc. are stored on a remote server and are accessed by students through the WWW. Tutors have convenient on-line access to student groupings to enable marks entry. Student preferences and settings, along with marks etc that make up the assessment profile of the students model, are available to the student.

\section{References}

Allert, H., Dhraief, H, \& Nejdl, W. (2002). Meta-level category 'Role' in metadata standards for learning: instructional roles and instructional qualities of learning objects. Retrieved 10th January 2003 from http://www.cosignconference.org/cosign2002/papers/Allert.pdf

Alty, J. L. (2002). Dual coding theory and computer education: Some media experiments to examine the effects of different media on learning. ED-MEDIA 2002, World Conference on Educational Multimedia, Hypermedia \& Telecommunications, Dever, Colorado, AACE.

Brusilovsky, P. (2000). Adaptive hypermedia: From intelligent tutoring systems to web-based education. Intelligent Tutoring Systems. Montreal, Canada: Springer-Verlag.

Brusilovsky, P., Schwarz, E. \& Weber, G. (1996). A tool for developing adaptive electronic textbooks on the WWW. Proceedings of WebNet'96, World Conference of the Web Society, San Francisco, CA.

Eklund, J. \& Brusilovsky, P. (1998). The value of adaptivity in hypermedia learning environmnet: A short review of emperical evidence. Workshop on Adaptive Hypertext and Hypermedia - HYPERTEXT 98, Pittsburgh, PA, USA.

Felder, R. (1993). Reaching the second tier: Learning and teaching in college science education. Journal of College Science Teaching, 23(5), 286-290.

Jonassen, D., Peck, K. L. \& Wilson, B.G. (1999). Learning with technology: A constructivist perspective. Upper Saddle, NJ: Merrill, Prentice Hall. 
Introducing Instruction into a Personalised Learning Environment

Jonassen, D. H., Dyer, D., Peters, K., Robinson, T., Harvey, D., King, M., \& Loughner, P. (1997). Cognitive flexibility hypertexts on the Web: Engaging learners in meaning making. In B. Khan, Web-based instruction (pp. 119-134). Englewood Cliffs, NJ: Educational Technology Publications.

Kurzel, F. \& Slay, J. (2003). The Development of a Personalised Learning Environment (PLE). 4th International Conference on Information CommunicationTechnologies in Education, Samos, Greece.

Kurzel, F., Slay, J. \& Chau, Y. H. (2002). Towards an adaptive multimedia learning environment. Proceedings of the 2002 Informing Science and IT Education Conference, Cork, Ireland.

Kurzel, F. Slay, J.\& Hagenus, K. (2003). Personalising the Learning Environment. Proceedings of the 2003 Informing Science and Information Technology Education, Pori, Finland, 589-596.

Martinez, M. (2001a). Foundations for personalised Web learning environments. Journal of Asynchronous Learning Networks, 4 (2).

Martinez, M. (2001b). Key Design Considerations for Personalised Learning on the Web. Educational Technology \& Society, 4 (1), 26-40.

Oppermann, R., Rashev, R., \& Kinshuk (Eds.). (1997). Adaptability and adaptivity in learning systems. Knowledge Transfer. London, UK: Pace.

Sampson, D., Karagiannidis, C. \& Kinshuk (2002). Personalising learning: educational, technogical and standardisation perspective. Interactice Educational Multimedia, 4, 24-39.

SCORM (2003). Sharable Content Object Reference Model (SCORM) 1.2.

Slay, J., Quirchmayr, G., Kurzel, F. and Hagenus, K. (2003). Adaptive learning environments for CS education - From AMLE to live spaces. ACE2003, Adelaide, South Australia, Australia, Conferences in Research and Practice in Information Technology.

Voigt, C. \& Swatman., P. (2003). Learning to learn: HCI-Methods for personalised eLearning. 10th International Conference on Human-Computer Interaction, Crete, Greece.

\section{Biography}

Frank Kurzel is a lecturer in the School of Communication, Information and New Media of the University of South Australia. He has been the Program Director for the Multimedia Studies Major within the Bachelor of Arts program at the University of South Australia. He has had extensive experience in Education, Computer Science and Multimedia areas. His research interests include web-based instructional systems to support his teaching, and the integration of Intelligent Tutoring Systems technology into hypermedia environments. He is also interested in instructional methodologies and enhancing the educational environment. 